sections which deal with the esters, ethers, xanthates and other derivatives of cellulose, with valuable discussions on the chemical reactivity of cellulose and on the degradation of its derivatives.

In the first section of the third part there is $a$ return to fundamental considerations, with authoritative and clear accounts of important physical features such as the solubility of cellulose and its derivatives, the thermodynamic properties of these solutions, the problems arising in the determination of molecular weights of macromolecular substances, theories of viscosity for dilute solutions of long-chain compounds, and a discussion of flow properties, including rheological phenomena. Next there is a section on the mechanical properties of cellulose followed by one on tests for cellulose and a series of appendixes in which are gathered together a whole host of data which will be invaluable to all whose work is in the cellulose field. Only those who have experienced it can appreciate fully the difficulty of finding such facts in the immensely scattered literature.

It will be clear from this account that this work is a book of reference rather than a text-book. Much of its usefulness will depend, therefore, on the quality of the indexing. Two indexes are provided at the end of the third book-an author index of fortyone closely printed pages and a subject index of seventy-four similar pages. Like the rest of the book, these are excellently done, and in so far as I have tested them they have been found to be readily usable, comprehensive and accurate. There is no doubt that this will long be regarded as a standard work on the subject, and the editors, authors and publishers are to be congratulated on the completion of this revised and augmented second edition.

E. L. Hrast

\section{MATHEMATICS FOR CHEMISTRY STUDENTS}

Mathematics for the Chemist

Mathematical Analysis for Chemists, Physicists and Chemical Engineers. By Prof. G. J. Kynch. Pp. vii +356. (London: Butterworths Scientific Publications; New York: Academic Press, Inc., 1955.) $30 s$. net.

DROF. G. J. KYNCH'S book is intended to meet the needs of students taking honours courses in chemistry, to provide a text with emphasis on the applications of mathematics, and to serve as a reference book for practising chemists and biochemists. Although written by a professional mathematician, it aims at being intelligible and useful in its field, and a characteristic is the brief yet reasonably strict nature of the methods used. Many results of integrations are merely stated, but the reader should easily find them by using methods which are explained.

The differential and integral calculus, series, exponential, logarithmic and hyperbolic functions, complex numbers, differential equations, determinants, vectors, Fourier series and spherical harmonics are included. An account of curvilinear co-ordinates and their applications would have been useful and could have taken the place of some of the text on approximate solution of equations and numerical methods. The treatment throughout is clear and interesting, the chapter on series being particularly good, and the book can be strongly recommended. The exercises call for thought rather than use of formulæ, and contain some useful additions to the text. References to books are given at the ends of the chapters. The book may not supply all the needs of users the author has in mind, who will want to know something about contour integrals, matrices and elementary group theory, but it provides a sound basis for future extension of knowledge.

The book is evidently based on teaching experience and a knowledge of the special difficulties of students of chemistry ; many matters passed over in purely mathematical books are clearly explained, and cases where errors easily arise are pointed out. It may be suggested, with due deference, that pure mathematicians could with advantage look through the book with reference to their own courses. When the lectures to chemistry students are taken by a junior on the mathematics staff, the book will be of great assistance to him in pointing out the needs of the students and the kind of treatment which is desirable.

\section{NATURE CONSERVATION FOR TEACHERS}

Handbook for Teaching of Conservation and Resource-Use

Prepared by the National Conservation Committee of the National Association of Biology Teachers in conjunction with the American Nature Association. (Richard L. Weaver-Project Leader.) Pp. 500. (Danville, Ill. : Interstate Printers and Publishers, Inc., 1955. Obtainable from Project Leader, National Association of Biology Teachers, P.O. Box 2073, Ann Arbor, Mich., U.S.A.) 4 dollars.

A PUBLIC awareness of the importance of wise A use and management of natural resources is highly desirable, particularly in view of the evergrowing demands which increasing world population makes upon them. In the United States the National Association of Biology Teachers has aimed at increasing this awareness by its conservation project, seeking to introduce conservation studies into schools wherever possible. The word conservation is here used in its widest sense-virtually an attitude of mind towards natural resources, akin to that of the ecologist regarding mankind as a biotic factor in the general scheme of Nature.

This book, which has been prepared for teachers, describes all possible methods of teaching conservation, in the class-room, school grounds and the field, sources of help for the teacher from the State and community, and schemes for extending interest in conservation teaching beyond the biology department. The matter is presented as reports, from individual schools, on actual projects which they have carried out. Examples are grouped under such headings as : films, slides and film-strips; radio programmes (the script of a radio skit broadcast by one school is given in full); aquaria and terraria; collection, preparation and exhibition of specimens; nature trails and sanctuaries.

One can find good ideas in these accounts which could be adapted to the rather different organization of teaching in Great Britain, but unfortunately they are buried in such a welter of blatantly obvious detail that one wearies of the search. For example, under 